\title{
EXAMINATION OF HAUSA TERMS AND CONCEPTS USED OVER ELECTRONIC MEDIA IN THE WESTERN HAUSA DIALECT AREA
}

\author{
USMAN AHMADU MOHAMMED \\ Nigerian Defence Academy - Kaduna
}

\begin{abstract}
The study is set up to examine Hausa terms and concepts used over the Nigeria electronic media. Specifically the study analyses the use of Hausa in the eastern Hausa dialect area where we sample Katsina and Sokoto States in Nigeria. Through various instruments of research, the study comes up with various performances of the Hausa Broadcasters in terms of IOVs, IOAs, IOCs, and IOIs.

The study identifies that there are various degrees of variations among Hausa Broadcasters in the use of terms and concepts in the electronic media in the western Hausa dialect area. These variations are observed at different levels i.e. among Hausa Broadcasters in the same electronic media within the same dialect area and across electronic media. These variations occasion various degrees of performances among Hausa Broadcasters in terms of IOAs. The study further identifies various degrees of performances in terms of IOCs, which result in various degrees of performances in terms of IOls.
\end{abstract}

\section{Objectives}

The general aim of the study is to examine the nature and use of Hausa in the electronic Media in order to observe "in/out-house inconsistencies" and "linguistic mismanagement" resulting from ad hoc use in order to cope with the trend for the development of the society. Specifically, the study will look at:

a. The use of terms and concepts in various electronic Media that broadcast News and feature programmes in Hausa within the Western Dialect Area.

b. The level of adequacy in the use of terms and concepts among Hausa Broadcasters/Editors.

c. The level of "in/out-house" consistencies and inconsistencies in the use of the terms and concepts among the Hausa Broadcasters/Editors.

d. The perception and understanding of the translated versions by the audience who listen to News and programmes in Hausa within the Area.

e. Problems associated with Hausa translations in the broadcast Media. 


\section{Method and Procedures}

\subsection{Research Method}

For this type of study various approaches may be used depending on the focus and the scope of the study.

Linguists, Sociolinguists and Scholars interested in the use of language have designed various approaches, which are aimed at determining of the use language(s) in its social context. The consensus among these Scholars is that this type of Research may be handled in different ways depending on the aims and objectives of the Research. W.N. Francis (1983) in his book titled: Dialectology: An Introduction identifies four approaches viz: a) the Traditional Approach which focuses on past events. Thus this type of approach is Diachronic and item centred i.e. historical in nature b) the Structural Approach which is not historical in nature i.e. Synchronic. This approach is essentially system centred. The Structural approach has always been concerned with the forms c) the Generative Approach which is panchronic. This approach is rule centred. The Generativists use this approach. These Scholars hold the view that language is rule governed. According to them to learn a language is to internalise the rules that governed the use of that language. d) the Sociolinguistic Approach is also Panchronic but Speaker centred. The Sociolinguistic Approach is concerned with who speaks what, with whom, where and when? This type of analysis investigates language in the social context. Thus our study falls within the scope of the Sociolinguistic Approach since we are concerned with the investigation of Hausa in the electronic Media.

In as much as we are interested in determining the cases of variations in the use of Hausa terms and concepts within and across the Media establishments our standard is the Standard Hausa, which is mainly based on the Kano dialect. Hausa in the Media: A Lexical Guide by McIntyre and Meyer-Bahlburg (1991) serves as the reference guide in the identification of the case or cases of variations in the use of terms and concepts. That means that the terms and/or concepts used in any Media establishment(s) are checked against the form(s) in the reference Guide. This is in order to determine case or cases of in-/out-house inconsistencies.

The second Method adopted for the analysis in this research is the Analytical Survey Method, which is not only descriptive in nature but also interpretative in its statistical sense. Statistics, which is part of the Analytical Survey Method, is used in this research to determine various degrees of variation in the use of terms and concepts in electronic Media.

The Analytical Survey Method presents an interesting description of the method, which is aimed at reducing data to figures for the sake of interpretations. There figures that represent different statistical observations are used to unravel certain realities. The analytical survey method comprises two components, each of which is determined by certain statistical activities aimed at the classification and 
organisation of the data. The components of the Analytical Survey Method are: a) Descriptive Statistics and b) Inferal Statistics. For the sake of this study we consider Descriptive Statistics, which comprises statistical observations such as: Mean, Standard Deviation, Average Deviation and Dispersion Range. These statistical observations are measurements that are classified under the Central Tendency (we are going to discuss these statistical observations further below). Two scales are used in this research to determine the two instances in the use of terms and concepts. These instances are: a) the inconsistencies in the use of terms and concepts where we distinguish between the degree of inconsistencies within each Media establishment i.e. in-house inconsistencies and b) the degree of inconsistencies across Media establishments i.e. out-house inconsistencies. For these types of considerations the statistical units of measurements we use are: a) the instances of inconsistencies among the respondents within or across the Media establishments are measured with the statistical unit referred to as the "Instance of Inconsistency" (henceforth $I O I$ ) while b) the adequacies of the renditions of terms and concepts from the SL to the TL is measured with the statistical unit referred to as the "Instance of Adequacy" (henceforth $I O A$ ) and the instances of variations among the respondents within or across the Media establishments are measured with the statistical unit referred to as the "Instance of Variation" (henceforth $I O V$ ) (the explanations of these statistical units will be presented further below). In order to reinforce the Descriptive Method we thought necessary and reasonable to adopt what Milroy (1987:3) refers to as the "Introspective Method" which according to him provides "accessibility to linguistic structures and organisations". The Introspective Method allows the researcher to use his competence in order to determine certain situation i.e. to identify, describe, and interpret linguistic phenomena. Leedy (1974:30) argues that the Descriptive Method is the "intense looks with accuracy at a phenomenon of the moment and describe what precisely what one has seen".

\subsection{Sampling}

Sampling procedures in this research takes into account some selected variables such as the dialectal differences, the educational attainment, and the experience of the broadcasters. Sampling procedures determine the universe of the research and its populace. The criteria used in the selection of this representative sample are related to whether the area of broadcast is originally Hausa speaking area i.e. endoglotic or the area is not originally Hausa speaking area i.e. exoglotic. Within the endoglotic area we consider Sokoto and Katsina States representing the Western Hausa dialects. In sum we have six (6) Media establishments. Hausa Editors/Broadcasters in all these electronic Media in these States are administered the Questionnaire designated to them i.e. the Questionnaires for Hausa Broadcasters/Editors.

The theoretical basis of sampling adopted for the selection of Hausa Listeners is from Labov's (1972b:37) concept of "random sampling". This theoretical 
concept advocated by Labov (op.cit.) is meant to select Respondents through a process where each individual within the area of the study is given a chance of being considered as a Respondent. A technique that is said to involve randomisation, various procedures are adopted. Among these procedures include: a) Roulette Wheel, b) Lottery Method, c) Table of random numbers etc. These procedures of random sampling are aimed at arriving at an un-bias sample. The central idea underlining this concept is to extract from the target population i.e. the entire population under study, a Research population i.e. a Research sample devoid of bias. The number of hundred (100) Respondents is selected through this process in each State sampled out here for the purpose of this study. Two hundred (200) Respondents/Hausa Listeners are sampled out of two States sampled here for the sake of this study. These Respondents are administered the appropriate Questionnaires for the Hausa Listeners/Viewers. The sampling procedure does not take into account social variables such as sex, educational background, and age.

\subsection{Statistics}

Statistics is yet another instrument used in this study. Statistics is a scientific means of taking numerical facts and translate them meaningfully. In the study Statistics is used as an instrument of interpretation while the Questionnaires are used for the exploration of the field of the study. Statistics helps in the interpretation of the product obtained from the field of study. Statistics is used to determine with accuracy the levels adequacies, consistencies and inconsistencies among the electronic Media in the uses of terms and concepts. In order to measure statistically the degree of adequacies among the electronic Media, the unit of the measurement used is the "Instance of Variation" (henceforth IOV), which is the score as result of inadequate use of a term and/or concept. While the unit for the measurement of the consistencies is the "Instance of Inconsistency" (henceforth $I O I$ ) which is the score as result of inconsistent use of a term and/or concept. Statistics has its own characteristics in terms of organisation and classification of the data obtained. Since in the Research we use it (i.e. Statistics) as an instrument for the interpretation of the data obtained, it is deemed necessary to discuss these characteristics in order to understand the operational system of the instrument. The characteristics of the instrument i.e. Statistics are: a) Central Tendency, b) Data Spread, c) Relationship, d) Correspondence with Nature. In this study, we consider only two characteristics namely the Central Tendency and the Data Spread. We are concerned in this study with Descriptive Statistics, which does not only describe our present situation but also interpret the situation. 


\subsection{Theoretical Framework}

The Theoretical Framework adopted in this study is adapted from Simpson's (1985) "Translation Criticism" theory with some modifications due to the focus of our research, which is the case of the study of inconsistencies in the use of terms and concepts over the Media. Simpson's theory is based on "positive and negative points" of the translation in the electronic Media. This study is particularly concerned with the negative points since one of the objectives of this research is to determine the level of inconsistencies within each electronic Media and across the electronic Media which use Hausa for the broadcast of News and feature programmes. Moreover we intend to use the principle of Adequacy as reflected in Viney and Darbelnet (1958) in order to assess the level of adequacy of the terms and concepts used i.e. to determine whether the equivalence is well motivated. For instance when there is a case of multiple interpretations of a concept we use our standard obtained from the Hausa Lexical Guide to determine the most adequate interpretation in which the sub-categorisation frame is captured.

\section{Analyses}

In this Section we intend to observe and compare the Respondents' performances in terms of IOVs and IOAs within individual electronic Media in each State sampled here for the sake of this study. In addition the analyses are expected to reflect various degrees of IOIs among the electronic Media within the individual electronic Media and across electronic Media within the Area sampled here. These analyses are correlated with the characteristics of Hausa Listeners both within Area. In addition, the analyses are expected to reflect the extent to which these individual electronic Media converge and/or diverge in the application of terms and/or concepts over the electronic Media.

As said earlier, in the Western Hausa dialect area we have sampled two States: Sokoto and Katsina States in order to consider the performances of individual Hausa Broadcasters and the performances of each electronic Media in each State in terms of $I O \mathrm{Vs}$ and IOAs. The analysis of the instances leads us to the considerations the IOCs and the IOIs of each electronic Media within the "area". Comparison of these IOCs and IOIs are made within the electronic Media in the "area".

In Sokoto State there are three electronic Media out of which two are State owned Media while one is a Federal owned Media. The Rima Radio Sokoto is a State owned electronic Media. The four Respondents are Hausa Native Speakers of Hausa who possess a good competence in the two languages i.e. English and Hausa. Nevertheless, as said earlier the linguistic assets per se may not be enough to guarantee efficient communicative competence. An efficient commu- 
nicative competence requires linguistic technicalities that are acquired through formal training in Translation. It is observed that in most electronic Media formal training in Translation is not thought necessary to the Broadcasters. The lack of the formal training may contribute to inefficient linguistic manipulations for the purpose of Mass Communication. Another aspect that may contribute to inefficiency in Hausa language development may be also the educational backgrounds of the Hausa Broadcasters who mostly possess qualifications unrelated to broadcasting. It is always assumed that broadcasting in Hausa or any other language apart from English does not require any serious consideration. This assertion may be backed by the decision taken at the Meeting of News and TV-Programmes Managers in February 2000. The decision led to the cancellation of the Hausa Translation Section in all NTA Stations that broadcast programmes in Hausa. The problems that affect the use of the language i.e. Hausa are numerous most of which militate against the standardisation of the language in the Media. All the Respondents use only Sakkwatanci.

There are five Respondents in the Rima Radio. Mean of the Respondents of the Respondents in terms of IOVs is 92. The Standard Deviation of the Respondents in terms of IOVs is 36.67. The Average Deviation of the Respondents in terms of $I O V s$ is 16.4. From the individual deviations we can observe that four Respondents: A, B, C and $\mathbf{E}$ perform below the central point. Only one Respondent: D who performs above the central point. The highest performance in terms of IOVs is reflected against the Respondent $\mathbf{D}$ while the lowest performance of the Respondent is reflected against the Respondent $\mathbf{E}$. The Dispersion Range of the Respondents in terms of $I O V_{S}$ is 59. The Mean of the Respondents in terms of IOAs is 53. The individual deviations in terms of IOAs reflect the fact that the Respondent $\mathbf{D}$ who performs above the central point in terms of IOVs performs below the central point in terms of IOAs. Four Respondents: A, $\mathbf{B}, \mathbf{C}$ and $\mathbf{E}$ who perform below the central point in terms of IOVS perform above the central point in terms of IOAs. The Standard Deviation of the Respondents in terms of IOAs is 36.67. The Average Deviation in terms of IOAs is 16.4. The highest performance in terms of IOAs is reflected against the Respondent $\mathbf{E}$ while the lowest performance in terms of $1 O A s$ is reflected against the Respondent D. The Dispersion Range of the Respondents is 59 . When we consider the total scores of Respondents in both $I O V s$ and $I O A s$, we discover that the performance of the Respondents in terms of IOVs constitutes $63.44 \%$ while the percentage of the Respondents in terms of $I O A s$ constitutes $36.55 \%$. Thus we can observe that the percentage of performances of the Respondents in terms of $I O \mathrm{Vs}$ higher than the percentage of performances of the Respondents in terms of IOAs. The IOCs of Respondents represents $4.27 \%$ while the IOIs of the represents $95.72 \%$. This shows that the percentage of the performances of the Respondents in terms of IOIs is greater than their percentage of performances in terms of IOCs. 
The characteristics of the Respondents in the Sokoto State Television are not much different from the characteristics of the Respondents in the Rima Radio Sokoto especially in terms of linguistic potentialities. It can be observed that the Respondents possess good competence skills in the two languages i.e. Hausa and English in addition to the fact that all of them are Hausa Native Speakers of Hausa. As argued above linguistic assets are not enough to guarantee adequate performance. Though the Respondents are quite experienced in the job, the lack of formal training in Translation may be one of the sources leading to inadequate performances and variations in the uses terms and concepts. As also observed in all the electronic Media considered thus far, most of the Respondents possess educational backgrounds un-related to the field of broadcasting especially Broadcasters from the Hausa section of the electronic. The problem might have derived from the Theories of Mass Communication, which may be workable in monolingual situations where English is the sole language of broadcasts. The lack of proper consideration to other languages of broadcasts apart from English is endemic to all the electronic Media under investigation. Hausa that is widely adopted for broadcasts within and outside Nigeria suffers the same faith. This may be observed in the variations inadequacies and inconsistencies of performances of the Hausa Broadcasters in the use of terms and concepts.

The Mean of the Respondents in terms of IOVs of the Sokoto State Television is 84.83 . The individual deviations in terms of IOVS show that three Respondents: A, B and D score below the central point while the other three: C, E and $\mathbf{F}$ score above the central point. That means that the highest performances in terms of $I O \mathrm{Vs}$ are reflected against the Respondents whose individual deviations are above the central point while the lowest performances in terms of $I O V s$ are reflected against the Respondents whose individual deviations are below the central point. The Standard Deviation of the Respondents in terms of IOVs is 16.73 while the Average Deviation is 6.83 . The highest performance of the Respondents in terms of IOVs is reflected against the Respondents $\mathbf{E}$. The lowest performance of the Respondents in terms of $I O \mathrm{Vs}$ is reflected against the Respondent $\mathbf{B}$. Thus the Dispersion Range of the Respondents is 25. In terms of $I O A s$ the Mean of the Respondents is 60.16. The individual deviations of the Respondents in terms of IOAs reflect the fact that three Respondents: $\mathbf{C}, \mathbf{E}$ and F perform below the central point while the other three: $\mathbf{A}, \mathbf{B}$ and $\mathbf{D}$ perform above the central point. This means that those whose performances in terms of IOAs are above the central point reflect highest performances in terms of IOAs. Those Respondents whose performances are below the central point reflect performances lower performances in terms of IOAs. The Standard Deviation of the Respondents is 16.73 while the Average Deviation is 6.83. The highest performance in terms of IOAs is reflected against the Respondent $\mathbf{B}$ who virtually scores less in terms of $I O V s$ while the lowest performance in terms of $I O A s$ is reflected against the Respondent $\mathbf{E}$. The Dispersion Range is 25 . The perfor- 
mances of the Respondents in terms of $1 \mathrm{OVs}$ constitute $58.5 \%$ while the performances of the Respondents in terms of IOAs constitute $41.49 \%$. This shows that the performances of the Respondents in terms of $I O \mathrm{Vs}$ are higher than their performances in terms of IOAs. In terms of IOCs the performances of the Respondents reflect $1.26 \%$ while their performances in terms of $I O I s$ reflect $98.73 \%$. This shows that the performances of the Respondents in terms of IOIs are higher than their performances in terms of IOCs. The percentage of performances in terms of IOVs of the Respondents in the previous electronic Media is higher than that of the Respondents in this electronic Media. In terms of IOAs the percentage of performances of the Respondents in the previous is equally higher than the percentage of performances of the Respondents in this electronic Media. In terms of IOIs and IOCs this electronic Media reflects lower percentages than the previous electronic Media. This means that the Respondents of the previous electronic Media reflect higher level of variations and higher level of consistencies than this electronic Media. From the percentages of performances in terms of IOAs of the two electronic Media, we can deduce that the previous electronic Media is more consistently inadequate in the uses of terms and concepts than this electronic Media. We can observe that the consistencies among the Respondents are not synonymous to adequacies. The Respondents may be consistent but reflect high level of consistency. When the percentage of the Respondents in terms of IOVs is high then automatically the percentage of the performance in terms of IOAs is low.

The NTA-Sokoto is the only Federal electronic Media in the State. The linguistic assets of the Respondents are similar to the previous electronic Media. The Respondents possess good linguistic backgrounds in the two: English and Hausa. In most cases the competences of the Respondents in English are higher than their competences in Hausa. This may raise the question of the conceptualisation of the terms, which are presented in English. In addition to this shortcoming most of the Respondents are not given formal training in Translation, which may help them use adequately their linguistic resources. The Respondents in NTA-Sokoto use both Kananci i.e. an Eastern variety of Hausa and Sakkwatanci i.e. a Western variety of Hausa. This tendency is not observed among the Respondents in the two previous electronic Media in the State. One thing, which is apparent among the Respondents in the electronic Media in this State as regard to the dialectal use is the fact that the Respondents use more Sakkwatanci than Kananci. In fact the use of Kananci is not observed in any other electronic Media apart from NTA-Sokoto. This may be connected to the Federal nature of the institution. As observed in the previous electronic Media the Respondents possess educational qualifications un-related to Hausa broadcasting. It is assumed that educational background has nothing to do with the performances of the Broadcasters who may possess any educational background. In normal situations the broadcasters are expected to constantly develop 
the language of broadcast in order to meet up with the linguistic needs. The Broadcasters who possess educational backgrounds un-related to the language of broadcasts may not be capable to efficiently achieve this gigantic task. Thus we end up with instances of inadequacies and variations among the Broadcasters in the uses of terms and concepts over the electronic Media.

The Mean of the Respondents in terms of IOVs is 56.4. From these individual deviations we can observe that the four Respondents: B, C, D and $\mathbf{E}$ score below the central point while the Respondent: A scores above the central point. The Standard Deviation of the Respondents in terms of IOVs is 26.47 while the Average Deviation is 11.84. The highest score of the Respondents in terms of IOVs is reflected against the Respondent $\mathbf{A}$ while the lowest score is reflected against the Respondent $\mathbf{E}$. Thus the Dispersion Range of the Respondents in terms of IOVs is 45. In terms of IOAs the Mean of the Respondents is 88.6. The individual deviations of the Respondents in terms of IOAs reveal that the Respondents: B, C, D and $\mathbf{E}$ reflect performances above the central point while the Respondent $\mathbf{A}$ reflect performances below the central point. The highest performance in terms of $I O A s$ is reflected against the Respondent $\mathbf{E}$ while the lowest performance is reflected against the Respondent $\mathbf{A}$. The Dispersion Range of the Respondents in terms of IOAs is 45 . The performances of the Respondents in terms of IOVs constitute $38.89 \%$ while the performances of the Respondents in terms of $I O A s$ constitute $61.1 \%$. This shows that the percentage of the performances of the Respondents in terms of $10 \mathrm{As}$ is higher than their percentage of their performances in terms of IOVs. This is a rare case where the percentage of the performances of the Respondents is higher than the percentage of their performances in terms of IOVs. The percentages of performances of the Respondents in other electronic Media have always been lower than the percentages of performances of the Respondents in terms of IOVs. In terms of IOCs the NTA-Sokoto has the percentage of $7.72 \%$ and in terms of IOIs the percentage is $92.27 \%$. This performance is also unique in the sense that the Respondents reflect more cases of consistencies and adequacies than the previous electronic Media.

The Hausa Listeners/Viewers in this State i.e. Sokoto State prefer various electronic Media both within the State and outside. It is interesting to note that the Hausa Listeners/Viewers patronize electronic Media from the two Hausa dialect areas: the Western and the Eastern dialect areas. In addition to the local stations they (the Listeners/Viewers) listen to foreign electronic Media. Among these include the BBC-Hausa service, which has the highest percentage of Listeners followed by the VOA-service and the Radio Deutsche Welle. We can observe that the percentages of Listeners of foreign electronic Media are higher than the percentages of Listeners of local electronic Media. This may be due to nature of presentations in these foreign Media. The Hausa Listeners/Viewers also patronize TV-stations within the two dialect areas and from the Neighbo- 
uring Country: Niger Republic. This indicates that Hausa Listeners/Viewers in Nigeria listen to Hausa broadcasts from the Western electronic Media and African electronic Media that broadcast News and feature programmes in Hausa. Twenty per cent of the Hausa Listeners/Viewers in the State misunderstand Hausa terms and concepts over the electronic Media. This shows that Hausa Listeners/Viewers are not properly informed due to inadequate terms and/or concepts presented in Hausa programmes over the electronic Media. That is why it is essential to consider certain socio-linguistic factors in the process of Language Development. Forty per cent of the Hausa Listeners/Viewers have leant Hausa terms and concepts over the electronic Media. This means that Hausa Listeners/Viewers develop their language skills through electronic Media. By so doing they improve their cultures and approaches to realities because the new terms and concepts they acquire may carry some innovations. There are evidences that indicate that Hausa Listeners/viewers do learn Hausa terms and concepts over the electronic Media. This in turn indicates that in addition to the sources through which Listeners/Viewers develop their skills, electronic Media are sources through which they acquire new terms and concepts. Thus the Listeners/Viewers are at the mercy of the Media practitioners (Broadcasters) for adequate presentations of events. The Listeners/Viewers in most cases are polyethnic and multilingual. In spite of the fact that in this State the ethnic and linguistic homogeneity is more than other State, there is need to cater for the nonHausa Speakers as well as Hausa Native Speakers in the State in Hausa language development. We can observe that most of the Respondents have learnt the language i.e. Hausa within the Western Hausa dialect area. Never the less there are some Hausaphone and Hausaphile might have acquired the language elsewhere. The point is since the aim of the Media is to inform and educate among others, the language of broadcasts should be develop in a way that it would be accessible to as larger audience as possible. The issue of misconception and breakdown of communication do not arise when Hausa language development takes care of linguistic and ethnic realities of the Listeners/Viewers. This effort must be uniform within the electronic in the State and other Hausa broadcasting Media establishments within and outside the Country. The lack coordinated efforts result to various degrees of variations and inadequacies among the Hausa Broadcasters/Editors.

Katsina State is one of the two States sampled here to represent the Western Hausa dialect area. The Hausa Broadcasters/Editors in the electronic Media in Katsina State also possess a good linguistic competence in all the skills of the two languages i.e. English and Hausa. However, as observed earlier linguistic assets per se do not guarantee a good performance. Most of the Respondents here also have not received a formal training in Translation. It seems that there is an increased dependency on linguistic competence with little or no care about the linguistic performance of the Media practitioners. Under normal cir- 
cumstance the two linguistic aspects are both required in order to achieve better results in linguistic performance .The linguistic performance is acquired through linguistic rigor in which techniques of linguistic manipulation are acquired. We can observe that the Respondents use both Sakkwatanci and Kananci, which are the two main dialects. It is interesting to note that Katsinanci, which is supposed to be the major dialect of the State, is not used. However Hausa Native Speakers of Hausa from Katsina the Respondents prefer to use these two dialects. The educational backgrounds of most Respondents are also un-related to their profession. This may contribute to inefficient utilisation of their linguistic resources even if they have been expose formal training in Translation.

The Mean of the Respondents in terms of IOVs is 92.6. From the individual deviations of the Respondents in terms of IOVs we can observe that three Respondents: $\mathbf{A}, \mathbf{C}$ and $\mathbf{E}$ reflect performances below the central point while two Respondents: B and D reflect performances above the central point. The Standard Deviation of the Respondents is 44.54. The Average Deviation is 19.92. The highest performance in terms of IOVs is reflected against the Respondent B while the lowest performance is reflected against the Respondent $\mathbf{C}$. Thus the Dispersion Range of the Respondents is 68. The Mean of the Respondents in terms of IOAs is 52.4. The individual deviations from the central point reveals that two Respondents: B and D reflect performances below the central point while the other three Respondents: $\mathbf{A}, \mathbf{C}$ and $\mathbf{E}$ reflect scores above the central point. The Standard Deviation of the Respondents is 44.54 and the Average Deviation is 19.92. The highest performance in terms of IOAs is reflected against the Respondent $\mathbf{C}$ and the lowest performance is reflected against the $\mathrm{Re}$ spondent B. Thus the Dispersion Range of the Respondent is 68. It can be observed that the Respondents' performances in terms of IOVs constitute $63.86 \%$ while their performances in terms of $I O A s$ constitute $36.13 \%$. The percentage of performances of the Respondents in terms of IOVs is higher than their performances in terms of $I O A s$. In terms of IOCs the percentage of the performances of the Respondents constitutes $4.41 \%$ while the percentage of their performances in terms of $I O I s$ constitutes $95.58 \%$. We can observe that the percentage of the performances of the Respondents in terms of IOCs is greater than their percentage of performances in terms of IOIs.

The Katsina State Television is a State owned electronic Media. The Respondents in this electronic Media possess also a good linguistic competence in English and Hausa, which is their Mother Tongue. All the Respondents except the Respondent $\mathbf{E}$ have formal training in Translation. We expect to have an improvement in the performances of the Respondents in both IOVS and IOAs. This is due to the fact that the formal training in Translation may help the Respondents to efficiently utilise their linguistic resources. The problem may reside in their performances in terms of IOCs. This is because it may be difficult for the Respondents to possess the same approach to the linguistic assets in order to 
carry home a point from the SL to TL whose Speakers are linguistically and culturally different. This is to mean that the management of linguistic resources may vary from one individual to another leading to various levels of performances in terms of $1 O \mathrm{Vs}, I O A s$ etc. Another factor, which may contribute to various degrees of IOVs and IOAs, is the fact that most Media practioners do not possess relevant educational backgrounds that may be improved through formal training in Translation.

The Mean of the Respondents in the Katsina State Television in terms of IOVs is 70.6. The individual deviations show that three Respondents: $\mathbf{B}, \mathbf{C}$ and $\mathbf{E}$ reflect performances below the central point while the Respondents: $\mathbf{A}$ and $\mathbf{D}$ reflect performance above the central point. The Standard Deviation of the Respondents is 37.38 while the Average Deviation is 16.72 . From the individual Deviations we can equally observe that the highest in terms of $10 \mathrm{Vs}$ is reflected against the Respondent $\mathbf{D}$ while the lowest performance is reflected against the Respondent $\mathbf{E}$. Thus the Dispersion Range of the Respondents is 51. In terms of IOAs the Mean of the Respondents is 74.4. The individual deviations of the Respondents in terms of IOAs indicate that two Respondents: $\mathbf{A}$ and $\mathbf{D}$ reflect performances below the central point while the other three Respondents: $\mathbf{B}, \mathbf{C}$ and $\mathbf{E}$ reflect performances above the central point. The Standard Deviation of the Respondents in terms of IOAs is 37.38 while the Average Deviation is 16.72. These individual Deviations reflect various levels of performances among the Respondents in terms of IOAs. The highest performance of the Respondent in terms of IOAs is reflected against the Respondent $\mathbf{E}$ while the lowest performance is reflected against the Respondent $\mathbf{D}$. Thus the Dispersion Range of the Respondents is 51 . The total scores of the Respondents in terms of IOVs constitute $48.68 \%$. The total scores of the Respondents in terms of $I O A s$ constitute $51.31 \%$. From these percentages of performances of the Respondents we can deduce that the percentage of performances of the Respondents in terms of $1 O \mathrm{Vs}$ is lower than their percentage of performances in terms of IOAs. In terms of $I O C s$ the performances of the Respondents constitute $7.72 \%$ while in terms of IOIs the percentage of the performances of the Respondents constitutes $92.27 \%$. From these percentages of performances we can deduce that the percentage of performances in terms IOIs is higher than the percentage of performances in terms of IOCs. This indicates that the Respondents possess a high level of IOVs but lower level of IOCs. When we compare the percentage of performances of the Respondents in the Katsina State Radio with that of the Respondents in the Katsina State Television, we can deduce that the percentage of performances of the Respondents in the Katsina State Radio is higher. The Respondents in the Katsina State Television reflect higher performance in terms of IOAs in comparison with performance of the Respondents in the Katsina State Radio. In terms of $I O C s$ the performances of the Respondents among the Respondents in Katsina State Television is higher than the performance of the 
Respondents in the katsina State Radio. Thus the Respondents in the Katsina State Radio reflect higher performance in terms of IOIs.

The NTA- Katsina is a Federal owned electronic Media. The Respondents in the electronic Media are Hausa Native Speakers of Hausa from Katsina. Thus we expect that the Respondents may be Speakers of Katsinanci, which is one the Western dialects of Hausa. When we compare the competences of the Respondents in the two languages i.e. Hausa and English, we discover that the competence of the Respondents in Hausa more than their competence in English. This may be due the fact that they are Hausa Native Speakers of Hausa. A high competence in English is also desirable. This is because of proper conceptualisation of $\mathrm{t}$ information embedded in SL. In addition to the competences in the two working languages, there is a need of a linguistic technical expertise to render a concept from the SL to the TL. Here we observe that the Respondents in this electronic Media use several dialects from both the Western and the Eastern varieties. The question is whether the use of several dialects is informed by the linguistic and/or ethnic composition of the Listeners/Viewers. It is interesting to note that Respondents in the other two electronic Media in the State do note use several dialects. These Respondents like others do not possess educational backgrounds that are related to their profession. This may seriously affect their performances in terms of IOAs and IOCs. The formal training that the Respondents are supposed to acquire is based on their educational backgrounds. Their efficiencies may be higher when their educational backgrounds are related to their profession.

The Mean of the Respondents in terms of IOVs is 82.83. From the individual deviations of the Respondents in this electronic Media we can deduce that two Respondents: $\mathbf{B}$ and $\mathbf{C}$ reflect performances below the central point while four Respondents: $\mathbf{A}, \mathbf{D}, \mathbf{E}$ and $\mathbf{F}$ reflect performances above the central point. The Standard Deviation of the Respondents in terms of $1 O \mathrm{Vs}$ is 47.9 while the Average Deviation is 19.55. From the individual deviations we can observe that the highest performance of the Respondents is reflected against the Respondent $\mathbf{E}$ while the lowest performance is reflected against the Respondent $\mathbf{C}$. Thus the Dispersion Range of the performances of the Respondents is 78. The Mean of the Respondents in terms of IOAs is 62.16. Thus the individual deviations of the Respondents in terms of IOAs indicate that four Respondents: $\mathbf{A}, \mathbf{D}, \mathbf{E}$ and $\mathbf{F}$ reflect performances below the central point while two Respondents: $\mathbf{B}$ and $\mathbf{C}$ reflect performances above the central point. The Standard Deviation of the Respondents in terms of IOAs is 47.89 while the Average Deviation is 19.53. The highest performance in terms of $I O A s$ is reflected against the Respondent $\mathbf{C}$ while the lowest performance in terms of IOAs is reflected against the Respondent $\mathbf{E}$. Thus the Dispersion Range of the Respondents in terms of $I O A s$ is 78 . The total scores of the Respondents in terms of $I O V s$ constitute $58.12 \%$. The total scores of the Respondents in terms of IOAs constitute $42.87 \%$. We can 
observe the percentage of performances of the Respondents in terms of IOVs is greater than the percentage of their performances in terms of IOAs. In terms of IOCs the percentage of performances of the Respondents is $3.67 \%$ while in terms of IOIs the percentage of their performances constitute $96.32 \%$. The highest percentage of performances in terms of IOVs is reflected against the Katsina State Radio then followed by the NTA-Katsina and then the Katsina State Television. The highest percentage of performances in terms of IOAs is reflected against the Katsina State Television then followed by the NTA-Katsina and the Katsina State Radio. In terms of IOCs the Katsina State Television reflects higher percentage of performances followed by the Katsina State Radio and then the NTA-Katsina.

The frequencies of listening habits of the Listeners/Viewers in Katsina State are considerably high. This results from the increased dependency on the electronic Media for News and feature programmes in Hausa. A high percentage of Listeners/Viewers prefer to listen to Hausa programmes in the Radio stations. Television stations are mostly preferred for English programmes. Listeners/Viewers in the State listen to various electronic Media both Radio and Television stations from the two Hausa dialect areas. In addition to the electronic Media in the State and neighbouring States, the Listeners/Viewers in the State listen to Western Radio Stations that broadcast in Hausa. The BBC-Hausa service has the highest percentage of Listeners followed by the VOA-Hausa service. From the percentages of Media preferences of the Respondents we can deduce that there is an increased dependency of Western electronic Media. This may be due to the presentations of the Hausa programmes in these electronic Media. It is observed that a high percentage of Listeners/Viewers misunderstand Hausa terms and concepts used in the Hausa programmes over the electronic Media. This means that the Media practitioners need to do more about the manipulation of linguistic resources in order to render certain concepts especially those which are alien to the culture of the speakers of the language i.e. Hausa. Though ethnic and linguistic homogeneity in this State are quite high it is necessary in the process of Hausa language development to take care of certain socio-linguistic factors that are related to Hausa Speakers in others heterogeneous States.

The Respondents in the electronic Media in Western Hausa dialect area are characterised by various performances in terms of IOVs, IOAs, IOIs and IOCs. In the electronic Media in Sokoto we observe that the highest performance in terms of IOVs is reflected against Rima Radio seconded by Sokoto State Television and then the NTA-Sokoto. In terms of IOAs the highest performance is reflected against the NTA-Sokoto seconded by the Sokoto State Television and then the Rima Radio. In the electronic Media in Katsina State the highest performance in terms of IOVs is reflected against Katsina State Radio seconded by the NTA-Katsina and then the Katsina State Television. In terms of IOAs the 
highest performance is reflected against the Katsina State Television seconded by the NTA-Sokoto and then the Katsina State Radio. When we consider the electronic Media in the Western Hausa dialect area we observe that the highest percentage of performance in terms of IOVs is reflected against the Katsina State Radio seconded by the Rima Radio-Sokoto then the Sokoto State Television then the NTA-Katsina then the Katsina State Television and then the NTASokoto. In terms of IOAs the highest performance is reflected against the NTASokoto seconded by Katsina State Radio then the NTA-Katsina then the Sokoto State Television then the Rima Radio Sokoto and then the Katsina State Radio. In terms of IOCs the highest performance among the electronic Media in Sokoto State is reflected against the NTA-Sokoto seconded by Rima Radio and then the Sokoto State Television. While in terms of IOIs the highest performance in the electronic Media in the State is reflected against the Sokoto State Television seconded by the Rima Radio and then the NTA-Sokoto. In the electronic Media in Katsina State the highest performance in terms of IOCs is reflected against the Katsina State Television seconded by the Katsina State Radio and then the NTA-Sokoto. While in terms of IOIs the highest performance is reflected against NTA-Katsina seconded by the Katsina State Radio and then the Katsina State Television. When we consider the Western Hausa dialect area we observe that the highest performance in terms of $I O \mathrm{Vs}$ is reflected against the Katsina State Radio seconded by Rima Radio then Sokoto State Television then NTAKatsina then Katsina State Television and then the NTA-Sokoto. While in terms of IOAs the highest performance is reflected against the NTA-Sokoto seconded by Katsina State Television then NTA-Katsina then Sokoto State Television then Rima Radio and then the Katsina State Radio. In terms of IOCs the highest performance is reflected against two electronic Media: NTA-Sokoto and the Katsina State Television followed by Katsina State Radio followed by Rima Radio followed by NTA-Katsina and then Sokoto State Television. While in terms of IOIs the highest performance is reflected against the Sokoto State Television seconded by the NTA-Katsina then Rima Radio then Katsina State Radio and then the Katsina State Television and the NTA-Sokoto.

\section{Summary}

We have observed various degrees performances in terms of IOVs, IOAs, IOCs and IOIs of Respondents in the electronic Media in the Western Hausa dialect area. Comparing the percentages of performances of the Respondents in the all the electronic Media here considered in terms of $I O V S$ we can observe that the highest percentage of performances of the Respondents is reflected against the Katsina State Radio with $63.86 \%$ then the Rima Radio-Sokoto with $63.44 \%$ then the Sokoto State Television with $58.5 \%$ then the NTA-Katsina with 
$57.12 \%$ then the Katsina State Television with $52.68 \%$ then the Katsina State Television $48.68 \%$ then the NTA-Sokoto with $38.89 \%$. We can observe various percentages of performances in terms of IOVS that vary from one electronic Media to another. We can observe that four electronic Media reflect percentages of performances in terms of IOVs above fifty per cent. There are eight electronic Media, which reflect percentages of performances in terms of IOVs below fifty per cent. Two electronic Media reflect percentages of performances in terms of IOVs below fifty per cent. In terms of IOAs the highest percentage of performances is reflected against the NTA-Sokoto $61.1 \%$ then the Katsina State Television with $51.31 \%$ then the NTA-Katsina with $42.87 \%$ then the Sokoto State Television with $41.49 \%$ then the Rima Radio-Sokoto with $36.55 \%$ then the Katsina State Radio with $36.13 \%$ then the. There are two electronic Media, which reflect percentages of performances above fifty per cent in terms of IOAs. In terms of IOCs the highest percentage of performances is reflected against Katsina State Television and the NTA-Sokoto with 7.72\% each then the Katsina State Radio with $4.41 \%$ then the Rima Radio with $4.27 \%$ then the NTA-Katsina with $3.67 \%$ then lastly the NTA-Sokoto with $1.26 \%$. From the percentages of performances in terms of IOCs we can deduce that none of the electronic Media reflect a percentage of performances above fifty per cent. We can further observe that in spite of the low percentages of performances in terms of $I O C s$, the electronic Media that reflect high percentages of performances in terms of IOAs are ranked low in terms of IOCs and those which reflect low performances in terms of IOAs are ranked high in terms of IOCs. In terms of IOIs the highest percentage of performances is reflected against the NTASokoto with $98.73 \%$ followed by the NTA-Katsina with $96.32 \%$ then the Rima Radio Sokoto with $95.72 \%$ then the Katsina State Radio with 95.29 then followed by two electronic Media: the Katsina State Television and the NTASokoto with both $92.27 \%$ each. From the percentages of performances in terms of IOIs we can deduce that the electronic Media that reflect low percentages of performances in terms of IOAs are those, which reflect high percentages of performances in terms of IOIs. We can further posit that the electronic Media reflect higher percentages of performances in terms IOAs but lower percentages of performances in terms of IOIs.

The percentages of performances in terms of $I O \mathrm{Vs}, I O A s, I O C s$ and $I O I s$ of the electronic Media in the Western Hausa dialect area reflect various realities in terms of the use of Hausa in the Nigerian electronic Media. These performances differ not only within the same electronic Media in the same State but also across electronic Media within and across the States. Many socio-linguistic factors contributed to these variations in the performances. Among these sociolinguistic factors include the educational linguistic and ethnic backgrounds of the Respondents. These factors seriously affect the communicative competence of the language i.e. Hausa, on which Millions of Hausa Listeners/Viewers de- 
pend for "participatory Democracy" in this era of the globalisation trend. It is vital to have a Hausa Language Unit that would be saddled with the responsibility of policing the use of the language.

BIBLIOGRAPHY

see p. $175-176$ 